\title{
Box-Cox Test: the theoretical justification and US-China empirical study
}

\author{
Tam Bang $\mathrm{Vu}^{\mathrm{a}^{*}}$ and Eric Iksoon $\mathrm{Im}^{\mathrm{a}}$ \\ ${ }^{a}$ College of Business and Economics, University of Hawaii Hilo, 200 K. Kawili street, Hilo, HI, 96720, USA
}

\section{A R T I C L E I N F O}

Article history:

Received 1 April 2010

Received in revised form

17 July 2010

Accepted 17 July 2010

Available online 17 July 2010

Keywords:

Model specification

Approximations

Box-Cox test

US-China study

\begin{abstract}
A B S T R A C T
In econometrics, the derivation of a theoretical model leads sometimes to two econometric models, which can be considered justified based on their respective approximation approaches. Hence, the decision of choosing one between the two hinges on applied econometric tools. In this paper, the authors develop a theoretical econometrics consumer maximization model to measure the flow of durables' expenditures where depreciation is added to former classical econometrics model. The proposed model was formulated in both linear and logarithmic forms. Box-Cox tests were used to choose the most appropriate one among them. The proposed model was then applied to the historical data from the U.S. and China for a comparative study and the results discussed.
\end{abstract}

(C) 2010 Growing Science Ltd. All rights reserved.

\section{Introduction}

Econometric analysis is an important tool in many fields of social sciences, business, and engineering. The derivation of a theoretical model might lead to two econometrics models, which can be considered justified based on their respective approximation approaches. Hence, the only way an economist can choose one between the two is by using applied econometric tools. To demonstrate this, the authors develop in this paper a theoretical model of consumer maximization problem. It is shown that once the first order condition is written, two econometric models can be obtained depending on whether a linear approximation or a log approximation is used. This justifies the use of the Box-Cox test to distinguish the more appropriate model from the less appropriate one. The traditional Keynesian theory posits that consumption depends on current disposable income. Keynes (1936) shows that this relationship is a fairly stable function. He argues that a higher absolute level of income will lead, as a rule, to a greater proportion of income being saved. However, empirical evidence does not support his claims. Inspired by the failure of Keynes' theory, Friedman (1957) develops a model of utility maximization that relates consumption to permanent income. He assumes that the representative consumer knows his lifetime income with certainty, and is able to save and borrow at will, subject to the constraint that any remaining debt is repaid at the end of his life. Under these assumptions, the individual will divide his lifetime income equally among different periods of his life. Hence, the consumer's consumption in any period does not depend on his current disposable income. Instead, it depends on his permanent income, which equals the average of his lifetime income. Just as Friedman (1957), Modigliani (1971) also believes that the current income is not crucial to consumption. But, he differs with Friedman by showing that the individual's consumption

\footnotetext{
* Corresponding author. Tel: 808-974-7462, Fax: 808-974-7685

E-mail addresses: tamr@hawaii.edu (T. B. Vu), 
depends on his lifetime wealth. The representative consumer is able to estimate his lifetime wealth with certainty. Based on this estimation, the individual determines his average consumption in the long run, and then sets current consumption to a fraction of that amount. That fraction equals the discounted present value of his wealth. Integration of the theories of Friedman (1957) and Modigliani (1971) leads to the "life cycle-permanent income hypothesis." The hypothesis refutes Keynesian argument that consumption depends on current disposable income alone.

Hall (1978) extends Friedman's and Modigliani's models to the case of 'consumption under uncertainty'. He assumes that the individual does not know his lifetime earnings with certainty. Hence, he has to maximize the expectation of his discounted utility. The result shows that the individual consumes the weighted average of his expected lifetime resources, which is equal to the expectation of the present discounted value of his earnings plus his initial wealth. Hence, consumption follows an autoregressive process of order one, an AR(1), in which the prediction of the dependent variable in period $t+1$ depends on its own value in period $t$ plus a stochastic disturbance. Furthermore, if the explanatory variable has a unit root, then the process is non-stationary. This is Hall's famous random walk hypothesis. While testing the theory, he finds that the stock prices significantly contribute to the prediction of future consumption. He argues that this happens because some part of consumption takes time to adjust to a change in permanent income. He suggests a modified version of the random walk hypothesis that allows a brief lag between permanent income and consumption. The reason behind this suggestion might be the linear form of his model, instead of the log form, which might fit US data better than its linear counterpart.

Mankiw (1982) expands Hall's framework to deal with consumer expenditure on durable goods. He also argues like Hall (1978) that the representative consumer maximizes the expectation of his discounted utility subject to his budget constraint: the present value of the lifetime stock of durables goods does not exceed initial wealth, plus the present value of lifetime labor earnings. Contrary to Hall's model, the durable goods depreciate over time. Hence, the stock of durable goods in any period equals the expenditure on durable goods, plus the previous period durable goods net depreciation. Mankiw (op. cit) assumes a quadratic utility function and an additive error term. He argues that if Hall is correct, consumer durables expenditures follow an ARMA $(1,1)$ process. The moving average parameter is related to the rate of depreciation. The empirical results give Mankiw an autoregressive process, an AR(1), instead. This implies that there is no difference between durable and nondurable goods and services concerning the relationship between consumption expenditure and its own lags. He is puzzled by the contradiction between his theoretical model of ARMA $(1,1)$ and the empirical result of AR(1) for the flow of consumer durables. It appears that depreciation rates play no role in determining consumer expenditure on durable goods. Again, this might be due to the linear form of his model, which he choses arbitrarily without any justification. Hansen and Singleton (1983) were the first to derive a theoretical model in log form, supposedly for composite consumption, but it does not involve the depreciation rate. This restricts the application of this model basically to non-durables and services. With a utility function in constant elasticity form and without rates of depreciation, the Euler equation for the growth rate of consumption is in multiplicative form. From this equation, a multiplicative error term gives an econometric model in log linear form. They conclude that consumption in log linear form follows a random walk. As they built the model mainly to address the asset price problem, the robustness of their model was not rigorously tested with empirical evidence. Also related to consumer durables is the Taylor series approximation of Mankiw (1985) which obtains a model in log form relating consumer durables to consumer nondurables or interest rates. Mankiw (op. cit) points out that log of consumer nondurables follows a random walk, as shown theoretically by Hansen and Singleton (1983). This means that log of consumer durables also follows a random walk. However, he does not carry out any empirical study to test his theory. Campbell and Mankiw (1989) develop a new theory wherein they consider that the assumption of one representative consumer in the conventional optimization problem is not appropriate for consumption. Instead, they introduce two representative consumers: one consumes his permanent 
income and the other consumes his current income owing to borrowing constraints. What they get from this assumption contrasts with the finding of Hansen and Singleton (1983), i.e., composite consumption in log-linear form does not follow a random walk. It is not clear, however, why they develop a theoretical model for a composite consumption function without depreciation rate. Caballero (1990) develops a one-consumer linear model which is similar to that of Mankiw (1982). Unlike Mankiw, he employs five annual or eight quarterly moving averages. Assuming that consumers adjust their expenditures in durable goods slowly, he revises Mankiw's model to allow for significant delays in consuming the goods. He claims that consumer durables expenditures follow an ARMA as in Mankiw's theoretical model: although each of the five or eight moving averages is insignificant, they together yield a significant moving average. Nevertheless, there is no econometric theory which justifies the assertion that the combination of insignificant moving average effects in an ARMA(1,5) or ARMA(1,8) is equivalent to a significant moving average effect in an ARMA(1,1) model.

Ermini (1988) attributes the failure of Hall's theory to the sampling and temporal aggregation problem (STA), because of which the econometrician observes only a sampled version of the actual time series or its temporally aggregated version. Instead of providing a theoretical model, Ermini (1988) uses these stylized facts in econometrics to suggest that the consumption expenditure should follow an IMA $(1,1)$ in linear form. Using quarterly data for the period 1947.1-1984.3 on the U.S. nondurable and service expenditure per capita, seasonally adjusted, and in constant 1972 dollars, he finds a positive and significant moving average. Ermini (1989) reinforces his IMA (1,1) model with a theoretical model. He verifies it with the U.S. monthly data on nondurable and service expenditures from 1959 to 1985 in constant 1982 dollars and finds a negative moving average. Since this is not what Hall (1978) finds, it again brings to the fore the possible misspecification of the model. Winder and Palm (1996) use a utility function in exponential form with nonseparable preferences between leisure and consumption. This results in a theoretical model in linear form, which is slightly different from that of Mankiw owing to the interaction between leisure and consumption. Assuming that the representative consumer follows rational expectation, they find that consumer expenditure on durable goods follows an ARIMA $(1,1,1)$ process, which is very close to Mankiw's model. Nevertheless, they do not explain the empirical result of an AR(1) in Mankiw (1982). Romer (2005) extends Mankiw's model by analyzing the stock of consumer durables and the flow of their expenditures, separately. He concludes that, theoretically, the stock of consumer durables follows a random walk, but the flow of their expenditures does not. His explanation is based on the involvement of the depreciation rates: intuitively, some of the durable goods purchased in period $t-1$ are still around in period $t$. Therefore, to keep the expected consumption in period $t$ at the same level, it is not necessary to buy one unit of goods all over again. The representative consumer has to purchase only enough to replace the fraction of the existing goods that depreciate. Thus, as of period $t-1$, part of the change in expenditure between $t$ and $t-1$ is predictable, i.e., the expenditure itself does not follow a random walk. By doing this, Romer tries to justify Mankiw's theoretical model of ARMA(1,1). Just as Winder and Palm (1996), he does not explain why Mankiw obtains an AR(1) empirically. Vu (2007) shows that durables expenditures can be approximated as an AR(1) process in log form but does not discuss the case of composite consumption. Owing partly to the controversial nature of the previous results, the focus of recent literature has shifted to either multivariate models instead of univariate ones, or panel data instead of time series. For example, Wachter (2006) develops a model of consumption in relation to interest rates whereas Pounder (2009) uses a panel data set to show that consumption depends less on permanent income in the data than on the theory. The authors' response to the inconclusive results of the univariate models is to develop a slightly different model for composite consumption, where depreciation rate is also added. Once the theoretical model is derived, it can be shown that two econometric models of linear or log form can be obtained. By testing these two models using the model transformations developed by Box-Cox (1964), it is shown that the results can be different for two particular countries: the U.S. and China. The disparity is then 
justified by pointing out the problems of using the Ljung-Box-Pierce tests for US data, as shown in Box and Pierce (1970) and Ljung and Box (1978). Finally, the unit root test, which was introduced by Dickey-Fuller (1979) and discussed in details in Hamilton (1994), is carried out to verify our theoretical and econometric models.

The remainder of this paper is organized as follows: Section 1 presents the proposed theoretical and econometrics models; Section 2 discusses the Box-Cox test; Section 3 presents a comparative empirical study between the U.S. and China; Section 4 presents the summary and conclusions of this work.

\subsection{Theoretical and Econometric Models}

A representative consumer who

Maximizes $E_{0} U=E_{0} \int_{t=0}^{\infty} e^{-\rho t} u_{t}\left[K_{t}\left(C_{t}\right)\right] d t$

subject to $\dot{A}_{t}=w_{t}-\dot{K}_{t}-\delta K_{t}+r A_{t}$

and $K_{t} \equiv-\delta K_{t}+C_{t}$

is considered here. This is a combination of the Ramsey-Cass and Mankiw (1982) models. If the depreciation rate is one, then one has to revert to the case of consumer nondurables and services as in Hall (1978). Or, one can consider this an extended version of the one in Hansen and Singleton (1983) and Lucas (1978), with depreciation rate added. Hence, this model is a generalization of a specific model for consumption of either durables or nondurables and services. The definitions of the variables are shown in Table 1.

\section{Table 1}

Variable Definitions

\begin{tabular}{ll}
\hline Notation & Definition \\
\hline $\mathrm{E}_{\mathrm{o}} \mathrm{u}$ & The expected lifetime utility at time zero \\
$\mathrm{u}_{\mathrm{t}}$ & Instantaneous utility with the usual properties of $\mathrm{u}^{\prime}>0$ and $\mathrm{u}^{\prime \prime}<0$ \\
$\mathrm{~K}_{\mathrm{t}}$ & The stock of durable goods \\
$\mathrm{C}_{\mathrm{t}}$ & The flow of durables expenditures \\
$\mathrm{A}_{\mathrm{t}}$ & The asset \\
$\mathrm{w}_{\mathrm{t}}$ & The wage income \\
$\mathrm{r}$ & The interest rate \\
$\rho$ & The time preferences \\
$\delta$ & The depreciation rate \\
\hline
\end{tabular}

From (3), one has,

$C_{t}=\dot{K}_{t}+\delta K_{t}$.

Combining (2) and (4) yields

$A_{t}=w_{t}-C_{t}+r A_{t}$. 
Thus, the current Hamiltonian is

$H_{c}=E_{0} u\left[K_{t}\left(C_{t}\right)\right]+\lambda\left(w_{t}-C_{t}+r A_{t}\right)$.

The first order condition is

$\frac{\partial H_{c}}{\partial C_{t}}=0 \rightarrow E_{0} u^{\prime}\left(C_{t}\right)=E_{0} u^{\prime}\left(K_{t}\right) \frac{\partial K}{\partial C}=\lambda$,

$\dot{\lambda}=-\frac{\partial H_{c}}{\partial A_{t}}+\lambda \rho \rightarrow-\frac{\lambda}{\lambda}=r-\rho$

and the tranversality condition implies that

$\lim _{t \rightarrow \infty} A u^{\prime}\left(C_{t}\right) e^{-\rho t}=0$.

From (7), one has

$$
\lambda=E_{0} e^{\ln U^{\prime}\left(C_{t}\right)} .
$$

Assuming that lnu' is normally distributed with mean $\mathrm{E}_{\mathrm{o}}$ lnu' and variance $v$, as shown in Romer (2008), one can write thus:

$$
\lambda=e^{E_{o} \ln u^{\prime}+(v / 2) t}
$$

$\ln \lambda=E_{o} \ln u^{\prime}+\frac{v}{2} t$

$-\frac{\dot{\lambda}}{\lambda}=-E_{o} \frac{u^{\prime \prime} C}{u^{\prime}} \frac{\dot{C}}{C}-\left(\frac{v}{2}\right)=\theta E_{o} \frac{\dot{C}}{C}-\frac{v}{2}$

Combining (8) and (11) yields

$\theta E_{o} \frac{C}{C}=\frac{v}{2}+r-\rho$.

Hence, the first order condition for the maximization problem is as follows:

$E_{0} \frac{C_{t}}{C_{t}}=\frac{1}{\theta}\left(\frac{v}{2}+r-\rho\right)$, where $\theta=-\frac{u^{\prime \prime C}}{u^{\prime}}$.

That is, $\theta$ is the agents' consumption elasticity of marginal utility and $\frac{1}{\theta}=\phi$ the agent's consumption elasticity of intertemporal substitution. 
If $\frac{1}{\theta}\left(\frac{v}{2}+r-\rho\right)=\alpha$, a constant, two econometric models can be obtained from Eq. (12). If one uses a linear approximation, then

$E\left(C_{t+1}\right)=\alpha+C_{t} \rightarrow C_{t+1}=\alpha+C_{t}+e_{t}$.

Now, if one uses a log approximation, then we have,

$\ln C_{t+1}=\beta+\ln C_{t}+v_{t}$.

\section{The Box-Cox test}

As both econometric models are theoretically correct, one may use Box-Cox test to choose one that is practically the most appropriate. Besides, two more tests would be performed to verify the theoretical and econometric models. For model specification tests, three types of transformations are available for data regression as discussed in Pindyck and Rubinfeld (1998): the Box-Tidwell, the original BoxCox, or the extended Box-Cox. The Box-Tidwell transformation allows a different transformation parameter for each independent variable. This transformation makes the models rather complicated and suffers from sensitivity to changes in sample sizes or changes in starting and ending points which makes it unpopular among practitioners. The Box-Cox test is used to test whether an empirical relationship is best described by a model in linear or log-linear form. In the original Box-Cox model, only the dependent variable is transformed. This makes the model overly simple and its robustness might be questionable if the data set suffers from serial correlation, which happens quite often in time series models. In the extended Box-Cox model, both dependent and independent variables are transformed as follows,

$Y^{(\lambda)}=x^{(\lambda)} \beta+\varepsilon$,

where

$$
\begin{aligned}
Y_{t}^{(\lambda)} & =\frac{Y_{t}^{\lambda}-1}{\lambda} \quad \text { if } \lambda \neq 0, \\
& =\ln Y_{t} \quad \text { if } \lambda=0 .
\end{aligned}
$$

and

$$
X_{t}^{(\lambda)}=\frac{X_{t}^{\lambda}-1}{\lambda} \text { if } \lambda \neq 0,
$$

$$
\begin{aligned}
& =\ln X_{t} \quad \text { if } \lambda=0, \\
& =X_{t}-1 \quad \text { if } \lambda=1 .
\end{aligned}
$$

In this paper, the extended Box-Cox test is performed as discussed in Greene (2003), which allows for auto-correlation, and therefore, represents better results. As both econometric models are in $\mathrm{AR}(1)$ process, the procedure determines whether an $\mathrm{AR}(1)$ in log form is more appropriate than the one in linear form. The log likelihood ratio to test the null hypotheses, $H_{0}: \lambda=\lambda_{h}$, is

$$
2\left[\ln \left(\lambda_{\max }\right)-\ln \left(\lambda_{h}\right)\right] \sim \chi_{(1)}^{2},
$$

where $\ln \left(\lambda_{\max }\right)$ is the maximum log likelihood value and $\ln \left(\lambda_{\mathrm{h}}\right)$ the log likelihood value for the hypothetical form. Under the null hypotheses, the ratio is distributed as chi-squared with one degree of freedom, whose critical values at $1 \%$ and 5\% significance levels are 6.63 and 3.84, respectively.

\section{US-China Empirical Study}

The Box-Cox test for the AR(1) models are performed as two approximations shown in Eq. (13) and Eq. (14). As the authors' theoretical model is a generalization of a specific model for consumption of either durables or nondurables and services, using a data set for composite consumption, including durables, nondurables and services, is justified. For the U.S., the quarterly data set of composite consumption is used for the period 1959.1-2008.4. The data set has a total of 200 observations, is taken from the National Income and Production Account (NIPA), and is in billions of chained 2005 
US dollars. Data for China is taken from China's Statistical Yearbooks published by National Bureau of Statistics of China. No quarterly data set for China is comprehensive, and the only yearly data set available is for per capita consumption in current Yuan for the period 1978-2008, which has a total of 31 observations. This dataset is multiplied by the data set on China's population to obtain a data set on composite consumption in current Yuan. Also, a chained consumer price index (CPI) is created for China equivalent to U.S. counterpart, using China's data on fixed base CPI with $1978=100$ and the moving based CPI with the previous year $=100$. The data set is then multiplied on composite consumption in current Yuan with the data set on chained CPI and divided by one billion to obtain China's yearly composite consumption for the period 1978-2008 in billions of chained 2005 Yuan. Table 2 presents the results from the extended Box-Cox tests for the two countries. From this Table, it can be seen that the Box-Cox test rejects the linear model in favor of the log model for U.S. consumption expenditures at $1 \%$ level. Hence, the log AR (1) model appears to fit the data better than the linear AR(1) model does for the U.S. For China, the Box-Cox test rejects the log model in favor of the linear model at $5 \%$ level. Hence, the linear AR (1) model appears to fit the data better than the log AR (1) model does for China.

Table 2

Results from the Box-Cox test

\begin{tabular}{lcccc}
\hline \multirow{2}{*}{ Model } & \multicolumn{2}{c}{ For the U.S. } & \multicolumn{2}{c}{ For China } \\
\cline { 2 - 5 } & Likelihood value & $\chi^{2}$ stat & Likelihood value & $\chi^{2}$ stat \\
\hline Log & -472.531 & 0.439 & -792.207 & $5.304^{* *}$ \\
Linear & -483.825 & $7.001^{* * *}$ & -780.182 & 0.007 \\
\hline
\end{tabular}

Maximum

Likelihood value

$-473.313$

$-791.204$

The $* *$ and $* * *$ indicate $5 \%$ and $1 \%$ significance levels, respectively.

As US data is available for both durables and nondurables expenditures, a robust check regression has been carried out separately for the two data sets. The results, shown in Table 3, are similar to the results in Table 2 for both data sets, that is, consumption in log form is still a more likely model for the US. One might ask why a model in log form is better than its linear counterpart for the U.S.

Table 3

Results for Durables and Non-Durables Expenditures of the US

\begin{tabular}{lcccc}
\hline \multirow{2}{*}{ Model } & \multicolumn{2}{c}{ Durables expenditures } & \multicolumn{2}{c}{ Nondurables Expenditures } \\
\cline { 2 - 5 } & Likelihood value & $\chi^{2}$ stat & Likelihood value & $\chi^{2}$ stat \\
\hline Log & -475.535 & 0.432 & -797.204 & 0.006 \\
Linear & -481.82 & $13.002^{* * *}$ & -800.187 & $5.966^{* *}$ \\
\hline Maximum & \multicolumn{3}{c}{-797.201} \\
Likelihood value & \multicolumn{2}{c}{-475.319} & \multicolumn{2}{c}{}
\end{tabular}

The ** and $* * *$ indicate $5 \%$ and $1 \%$ significance levels, respectively.

Theoretically, long time-series data usually suffers from autocorrelation, heteroskedasticity, and nonnormality of the error terms. If one of these problems occurs, the classical assumptions of OLS are violated, and the test results are no longer valid. While taking the first difference can eliminate autocorrelation problem, it cannot reduce the consequences from the other two. Taking the logs of each variable reduces the volatility, and therefore, may correct the problem of heteroskedasticity, and also making the error terms closer to normal. Empirically, as the consumption data set for the U.S. is a quarterly data set and six times larger than the one for China, it is more volatile than the Chinese counterpart. Another reason is that the U.S. has gone through many recessions and expansion 
periods, whereas China has been enjoying economic growth since 1978. As aggregate consumption can be written as the product of marginal propensity to consume and GDP, the volatility of the American GDP causes more volatility in consumption. Taking the logs will reduce the volatility and make the U.S. model fit the data better than its linear counterpart. Hence, an AR(1) model in log form is more suitable for U.S. consumption expenditures, while the opposite is true for China. To test the hypotheses concerning the problems with long time-series data, the Ljung-Box-Pierce tests have been run on the linear and log models for ten modified lags, using US data set. The results are presented in Table 4.

\section{Table 4}

The Ljung-Box-Pierce tests for the US data

Model in Linear Form $\quad$ Model in Log Form

\begin{tabular}{|c|c|c|c|c|c|}
\hline Modified Lag & Q-Statistics & p-value & Modified Lag & Q-Statisctics & p-value \\
\hline 1 & $3.92 * *$ & .048 & 1 & 0.32 & .783 \\
\hline 2 & $6.03 * *$ & .045 & 2 & 1.13 & .601 \\
\hline 3 & $8.94 * *$ & .041 & 3 & 1.21 & .758 \\
\hline 4 & $14.86^{* * *}$ & .008 & 4 & 1.93 & .825 \\
\hline 5 & $13.53 * *$ & .032 & 5 & 2.01 & .794 \\
\hline 6 & $12.86^{* *}$ & .049 & 6 & 2.12 & .623 \\
\hline 7 & $16.75^{* *}$ & .028 & 7 & 2.43 & .716 \\
\hline 8 & $21.52 * * *$ & .009 & 8 & 3.02 & .843 \\
\hline 9 & $17.46^{* *}$ & .047 & 9 & 3.68 & .764 \\
\hline 10 & $20.61^{* *}$ & .024 & 10 & 4.01 & .832 \\
\hline
\end{tabular}

The $* *$ and $* * *$ indicate $5 \%$ and $1 \%$ significance levels, respectively.

From this Table, it can be seen that the test performed on linear model rejects the null hypothesis, namely that all residuals follow a white noise process whereas the one performed on the log model fails to reject this null hypothesis for the US. All the $Q$ statistics for the log model are far below the Chi-square critical values. This confirms the authors' belief that US long time-series data suffers from autocorrelation, heteroskedasticity, and nonnormality of the error terms, and that taking the log of the series corrects these problems. From Eq. (13) and Eq. (14), composite consumption could follow a random walk with a drift, either in linear or in log form. Hence, the authors have performed the augmented Dickey-Fuller tests on both US and China data sets to see whether or not the log model for the US and the linear model for China have unit roots. The following model is used for a number of different lag lengths: 


$$
\Delta C_{t}=\beta_{0}+\beta_{1} C_{t-1}+\beta_{2} t+\sum_{i=1}^{k} \beta_{i} \Delta C_{t-i}+\varepsilon_{t} .
$$

The authors expected a unit root for the first lag, a statistically significant constant term, and no time trend for each of the two models. The tests are performed with one lag, two lags and three lags for each series. From Eq. (15), a set of three null hypotheses are tested:

$H_{01}: \quad \beta_{1}=0$

$H_{02}: \beta_{1}=\beta_{2}=0$

$H_{03}: \beta_{0}=\beta_{1}=\beta_{2}=0$

As the results for two lags and three lags are similar to the results with one lag, the results of only one lag are presented in Table 5. Based on these results, the authors could reject $\mathrm{H}_{03}$ for both series, but not $\mathrm{H}_{01}$ and $\mathrm{H}_{02}$. Hence, US composite consumption expenditures follow a random walk with a drift in log form, and those of China with a drift in linear form. These results confirm the authors' econometric models in Eq. (13) and Eq. (14).

\section{Table 5}

Augmented Dickey-Fuller tests on unit roots for Eq. (13) and Eq. (14)

Models US Model in Log Form China’s Model in Linear Form

\begin{tabular}{lccccc}
\hline Hypotheses & $\begin{array}{c}\text { Type of } \\
\text { Test } \\
\text { Statistics }\end{array}$ & Statistics & $\begin{array}{c}\text { Asy. Critical } \\
\text { Values for } \\
10 \%\end{array}$ & Statistics & $\begin{array}{c}\text { Asy. Critical } \\
\text { Values for } \\
10 \%\end{array}$ \\
\hline$H_{01}: \beta_{1}=0$ & $\tau$ & -1.968 & -3.13 & -2.31 & -3.76 \\
\hline$H_{02}: \beta_{1}=\beta_{2}=0$ & $\mathrm{~F}$ & 3.64 & 5.34 & 4.26 & 5.79 \\
$($ non-zero drift) & & & & & \\
\hline$H_{03}: \beta_{0}=\beta_{1}=\beta_{2}=0$ & $\mathrm{~F}$ & 4.97 & 4.03 & 6.94 & \\
(zero drift) & & & & & \\
\hline
\end{tabular}

\section{Conclusion}

In this paper, the authors have derived a general consumer maximization econometrics model. The proposed model is based on adding depreciation rate as part of the traditional model. It is explained how one can use the new method in both linear and logarithmic forms, and the Box-Cox test in determining the suitable one for authors' empirical data. The proposed method has been implemented for historical data sets of the U.S. and China for a comparative study. To justify the disparity between the results, the authors have performed the Ljung-Box-Pierce tests on US data and shown that taking the log of the series eliminates several time-series problems of this data set. Finally, the Dickey-Fuller test also has been carried out to verify the econometric models as discussed in the theoretical section.

In this context, it is worthwhile to highlight a small, but important point: As of now, the data set for China is too small to perform the Ljung-Box-Pierce test; therefore, when a larger data set is available, the procedure that has been applied to U.S. could be applied to China as well. Also, as the focus of 
this study has been on theoretical justification of the Box-Cox test for the consumer maximization problem, the problems of modeling other variables are left for future research.

\section{References}

Box, G.E., \& Cox, D. R. (1964). An analysis of transformations. Journal of the Royal Statistical Society, Series B, 26: 211-252.

Box, G.E., \& Pierce, D. (1970). Distribution of autocorrelations in autoregressive moving average time series model. Journal of the American Statistical Association, 65, 1509-1526.

Caballero, R.J. (1990). Expenditure of durable goods: A case for slow adjustment. The Quarterly Journal of Economics, 105(3), 727-743.

Campbell, J., \& Mankiw, N. G. (1989). Consumption, income, and interest rates: Reinterpreting the time series evidence. NBER Macroeconomic Annuals, 4, 185-215.

Dickey, D.A., \& Fuller, W. A. (1979). Distribution of the estimators for autoregressive time series with a unit Root. Journal of the American Statistical Association, 74, 427-431.

Ermini, L. (1988). Temporal aggregation and Hall's model of consumption behavior. Applied Economics, 20, 1317-1320.

Ermini, L. (1989). Excessive sensitivity of consumption and postponed revision of the optimum plan. Journal of Macroeconomics, 11(3), 409-422.

Friedman, M. (1957). A theory of the consumption function. Princeton University press, 1957.

Greene, W.H. ( 2003). Econometric analysis, Prentice Hall, New Jersey.

Hall, R. E. (1978). Stochastic implications of life cycle-permanent income hypothesis: Theory and evidence. The Journal of Political Economy, 86(6), 971-987.

Hamilton, J. (1994). Time Series Analysis. Princeton University Press, New Jersey.

Hansen, L. P. \& Singleton, K. J.(1983). Stochastic consumption, risk aversion, and temporal behavior of asset returns. The Journal of Political Economy, 91(2), 249-265.

Keynes, J. M. (1936). The General Theory of Employment, Interest, and Money. Macmillan, London.

Ljung, G. \& Box, G.E.(1978). On a measure of lack of fit in time series model. Biometrica, 65, 297303.

Lucas, R.F. (1978). Asset prices in an exchange economy. Econometrica, 46, 1429-1445.

Mankiw, N. G. (1982). Hall's consumption hypothesis and durable goods. Journal of Monetary Economics, 10, 417-425.

Mankiw, N. G. (1985). Consumer durables and the real interest rate. The Review of Economics and Statistics, 67(3), 353-362.

Modigliani, F. (1971). Monetary Policy and Consumption, Consumer Spending and Monetary Policy: The Linkages, Conference Series No. 5, Boston, Federal Reserve Bank of Boston.

National Bureau of Statistics of China, 1978-2009, China's Statistical Yearbooks, Beijing.

Pindyck, R.S. \& Rubinfeld, D. L. (1998). Econometric Models and Economic Forecasts, Irwin McGraw-Hill, Massachusetts.

Pounder, L., (2009). Consumption response to expected future income, Board of Governors of the Federal Reserve System. International Finance Discussion Papers, 971, 1-35.

Real GDP and Components. (2009). Bureau of Economic Analysis website, http://www.bea.gov.

Romer, D., (2005). Advanced Macroeconomics, Massachusetts: McGraw-Hill.

$\mathrm{Vu}$, T.B. (2007). An alternative approximation to consumer durables expenditures. Applied Economics Letters, 14,643-646.

Wachter, J.A. (2006). A consumption-based model of the term structure of interest rates. Journal of Financial Economics, 79(2), 365-399.

Winder, C. C. A. \& Palm, F. C. (1996). Stochastic implications of the life cycle consumption model under rational habit formation. Recherches economiques de Louvain, 62(3-4) 403-EOA. 